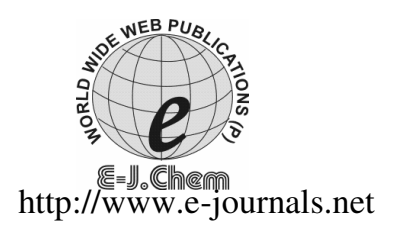

ISSN: 0973-4945; CODEN ECJHAO

E-Journal of Chemistry

2010, 7(4), 1562-1570

\title{
Crystal Structure, Spectroscopic and Thermal Investigations of a New 4-Ammonio-2,2,6,6- tetramethylpiperidinium Tetrachlorozincate(II)
}

\author{
M. EL GLAOUI ${ }^{\S}$, M.L. MRAD ${ }^{\S}$, E. JEANNEAU and C. NASR ${ }^{\text {J }^{*}}$ \\ ${ }^{\S}$ Laboratoire de Chimie des Matériaux, \\ Faculté des Sciences de Bizerte, 7021 - Zarzouna - Bizerte Tunisie. \\ Centre de Diffractométrie Henri Longchambon, \\ Université Claude Bernard Lyon 1, Villeurbanne Cedex, France. \\ cherif_bennasr@yahoo.fr
}

Received 31 July 2009; Accepted 25 September 2009

\begin{abstract}
The new complex of $\mathrm{Zn}$ (II) with 4-ammino-2,2,6,6tetramethylpiperidine, $\left[\mathrm{C}_{9} \mathrm{H}_{22} \mathrm{~N}_{2}\right] \mathrm{ZnCl}_{4}$, has been prepared and characterized by various physicochemical studies. This compound crystallizes in the monoclinic system, with the space group $\mathrm{P} 2{ }_{1} / \mathrm{c}$ and the following cell parameters: $\mathrm{a}=9.8682(7), \mathrm{b}=7.5164(5), \mathrm{c}=21.019(2) \AA, \beta=99.003(7)^{\circ}$, $\mathrm{V}=1539.8(2) \AA^{3}$ and $\mathrm{Z}=4$. The crystal structure was solved and refined to $\mathrm{R}=0.024$ using 3070 reflections. The atomic arrangement can be described by slightly distorted tetrahedral $\mathrm{ZnCl}_{4}{ }^{2-}$ anions and 4-ammmonio-2,2,6,6tetramethylpiperidinium cations holding together by different interactions. The four chlorine atoms of the $\mathrm{ZnCl}_{4}{ }^{2-}$ tetrahedron are acting as acceptors of hydrogen bonds. The crystal packing is influenced by cation-to-anion $\mathrm{N}-\mathrm{H} . . . \mathrm{Cl}$ and $\mathrm{C}-\mathrm{H} . . . \mathrm{Cl}$ hydrogen bonds leading to open framework architecture.
\end{abstract}

Keywords: Complex; X-ray crystal structure; IR spectroscopy; Impedance spectroscopy.

\section{Introduction}

Chemists and physicists of the solid state have shown an increasing interest in the study of the organic-inorganic hybrid materials in recent years owing to their potential fundamental and practical interest such as, fuel cell, liquid crystal-material development, second-order nonlinear optical (NLO) responses, magnetism, luminescence, photography and drug delivery, etc ${ }^{1-11}$. Moreover, in the organic inorganic hybrid metal halides, hydrogen bonds play an important role in stabilizing the 
frameworks of the organ ammonium cations and their counter inorganic species. The energetic of $\mathrm{N}-\mathrm{H}$...halide-metal hydrogen bonds and their possible role in supramolecular chemistry continue to attract much attention ${ }^{12}$. It is therefore important to design and synthesize novel hybrid compounds by reaction between the zinc chloride and an organic ligand containing N-H bonds. In the present investigation, we report the synthesis and the physicochemical characterization of $\left[\mathrm{C}_{9} \mathrm{H}_{22} \mathrm{~N}_{2}\right] \mathrm{ZnCl}_{4}$.

\section{Experimental}

Crystals of the title compound were prepared according to the following chemical reaction:

$$
\left[\mathrm{C}_{9} \mathrm{H}_{20} \mathrm{~N}_{2}\right]+2 \mathrm{HCl}+\mathrm{ZnCl}_{2} \longrightarrow\left[\mathrm{C}_{9} \mathrm{H}_{22} \mathrm{~N}_{2}\right] \mathrm{ZnCl}_{4}
$$

By slow evaporation of an aqueous solution of 4-ammino-2,2,6,6-tetramethylpiperidine, hydrochloric acid and zinc chloride. The crystals are stable under normal conditions of temperature and humidity. The chemical formula was determined during the X-ray crystal structure analysis.

\section{Investigation techniques}

\section{$X$-ray diffraction}

The characterization of these salts was carried out using X-ray diffraction, Infrared spectroscopy, thermal analysis and impedance spectroscopy. A single crystal was carefully selected under polarizing microscope in order to perform its structural analysis by X-ray diffraction. The intensity data were collected on an Enraf-Nonius MACH3 automated fourcircle diffractometer using the graphite monochromated MoK $\alpha$ radiation at $\lambda=0.7107 \AA$. The structure was solved by direct methods using the SIR $97^{13}$ program and refined by full matrix least-squares techniques using CRYSTALS ${ }^{14}$. The drawings were made with Diamond $^{15}$. All non-hydrogen atoms were refined anisotropically. The hydrogen atom positions were located by difference-Fourier synthesis and refined with riding restraints. Crystal data and experimental parameters used for the intensity data collection are summarized in Table 1. The main geometrical features of the different entities are given in Tables 2 and 3.

\section{Infrared spectroscopy}

The infrared spectrum was recorded in the range 4000-400 $\mathrm{cm}^{-1}$ with a "Perkin-Elmer FTIR-1000" spectrophotometer using a sample dispersed in spectroscopically pure $\mathrm{KBr}$ pellets.

\section{Thermal analysis}

Thermal analysis was performed using the "multimodule 92 Setaram" analyzer operating from room temperature up to $500{ }^{\circ} \mathrm{C}$ at an average heating rate of $5^{\circ} \mathrm{C} \cdot \mathrm{min}^{-1}$.

\section{Impedance spectroscopy}

Impedance spectroscopy was used to measure the electrical conductivity ${ }^{16-17}$. The impedance diagrams were recorded in the $5 \mathrm{~Hz}-13 \mathrm{MHz}$ frequency range using a Hewlett Packard HP 4192A analyser. To ensure electrical contacts, the two parallel surfaces of the sample (having a cylindrical shape) were coated by a layer of silver paint. The platinum wires and the sample were held in contact by a weak mechanical pressure controlled by a screw/spring system and transmitted by an alumina rod. 
Table 1. Crystal data, experimental parameters used for the intensity data collection, strategy and final results of the structure determination $\left[\mathrm{C}_{9} \mathrm{H}_{22} \mathrm{~N}_{2}\right] \mathrm{ZnCl}_{4}$

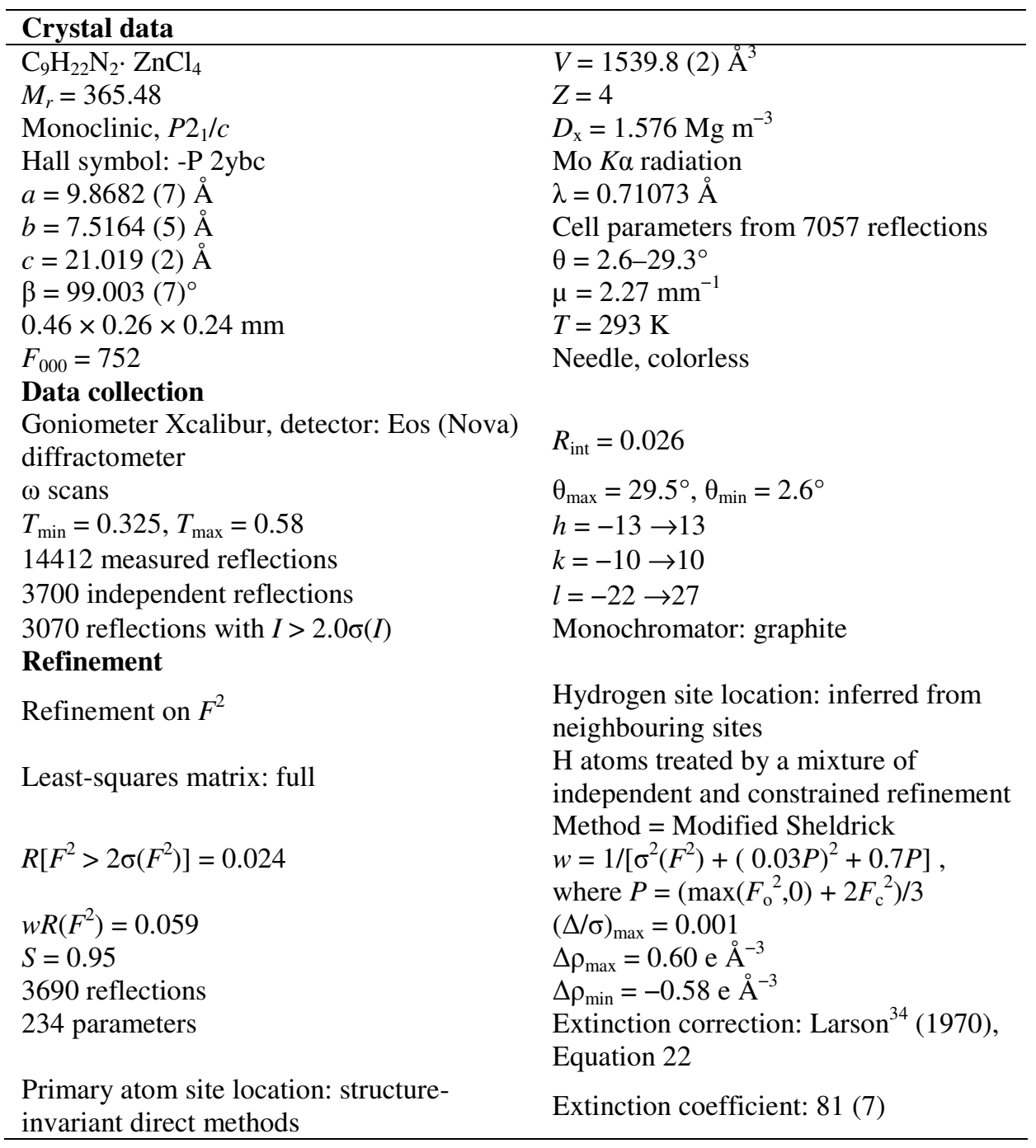

Table 2. Main inter-atomic distances $(\AA)$ and bond angles $\left(^{\circ}\right)$ in the inorganic groups of $\left[\mathrm{C}_{9} \mathrm{H}_{22} \mathrm{~N}_{2}\right] \mathrm{ZnCl}_{4}$

The $\mathrm{ZnCl}_{4}$ tetrahedron

\begin{tabular}{ccccc}
\hline Zn & Cl1 & Cl2 & Cl3 & Cl4 \\
\hline Cl1 & $\mathbf{2 . 2 9 6 4 ( 5 )}$ & $3.788(12)$ & $3.636(11)$ & $3.639(1)$ \\
Cl2 & $112.42(2)$ & $\mathbf{2 . 2 6 1 3 ( 5 )}$ & $3.721(1)$ & $3.637(8)$ \\
Cl3 & $106.12(2)$ & $111.06(2)$ & $\mathbf{2 . 2 5 2 8 ( 5 )}$ & $3.778(4)$ \\
Cl4 & $106.12(2)$ & $107.24(2)$ & $113.86(2)$ & $\mathbf{2 . 2 5 6 1 ( 5 )}$ \\
\hline
\end{tabular}


The 4-ammonio-2,2,6,6-tetramethylpiperidinium group

\begin{tabular}{llll}
\hline N1 - C1 & $1.496(2)$ & N1 - C1 - C2 & $110.21(14)$ \\
\hline C1 - C2 & $1.522(2)$ & N1 - C1 - C5 & $110.88(14)$ \\
C1 - C5 & $1.512(2)$ & C2 - C1 - C5 & $110.02(13)$ \\
C2 - C3 & $1.525(2)$ & C1 - C2 - C3 & $111.65(14)$ \\
C3 - N2 & $1.527(2)$ & C2 - C3 - N2 & $106.81(13)$ \\
C3 - C8 & $1.525(2)$ & C2 - C3 - C8 & $111.29(15)$ \\
C3 - C9 & $1.522(2)$ & N2 - C3 - C8 & $106.07(13)$ \\
N2 - C4 & $1.537(2)$ & C2 - C3 - C9 & $112.88(14)$ \\
C4 - C5 & $1.530(2)$ & N2 - C3 - C9 & $110.75(15)$ \\
C4 - C6 & $1.523(2)$ & C8 - C3 - C9 & $108.81(16)$ \\
C4 - C7 & $1.521(2)$ & C3 - N2 - C4 & $120.19(12)$ \\
& & N2 - C4 - C5 & $108.10(13)$ \\
& & N2 - C4 - C6 & $105.44(13)$ \\
& & C5 - C4 - C6 & $110.96(15)$ \\
& & N2 - C4 - C7 & $110.61(14)$ \\
& & C5 - C4 - C7 & $112.06(14)$ \\
& & C6 - C4 - C7 & $109.46(16)$ \\
& & C4 - C5 - C1 & $112.00(13)$ \\
\hline
\end{tabular}

\section{Results and Discussion}

\section{Structure description}

As shown in Figure 1, to ensure charge equilibrium, the organic species is doubly protonated at N1 and N2 nitrogen atoms. Thus, the structure associates to each 4-ammmoni-2,2,6,6tetramethylpiperidinium cation one tetrachlorozincte anion. Figure 2 shows that the atomic arrangement of the title compound can be described by inorganic $\mathrm{ZnCl}_{4}{ }^{2-}$ species isolated by the organic cations. These entities are held together by coulombic attraction and multiple hydrogen bonds to form a three dimensional infinite network. This figure shows columns, formed by two $\mathrm{ZnCl}_{4}{ }^{2-}$ anions and two 4-ammmoni-2,2,6,6-tetramethylpiperidinium cations, running along the $b$-axis at $x=1 / 2$ and $z=n / 2$.

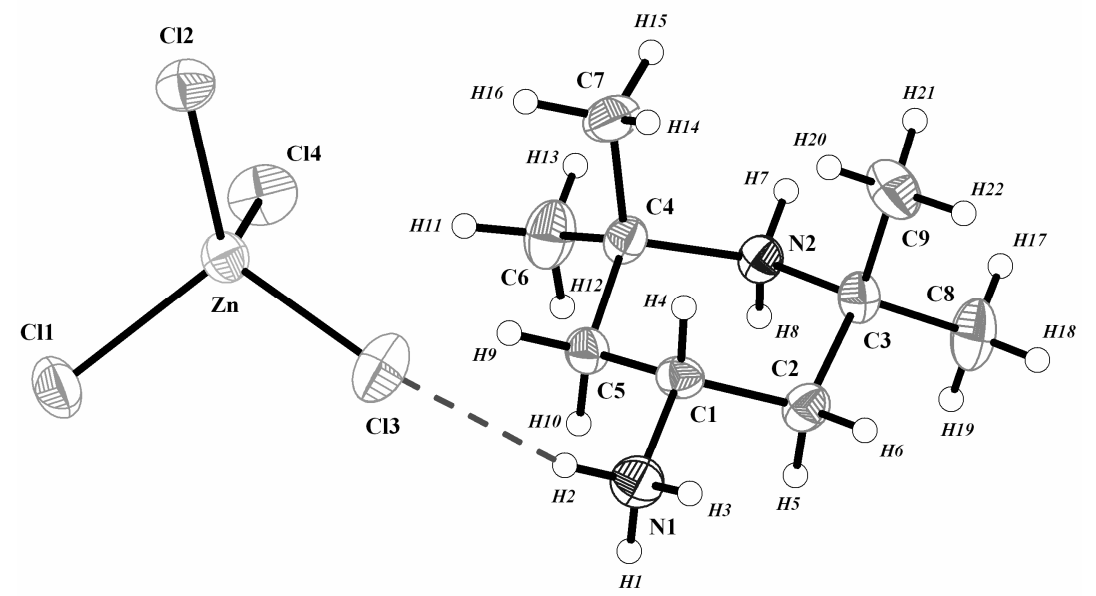

Figure 1. Asymmetric unit of $\left[\mathrm{C}_{9} \mathrm{H}_{22} \mathrm{~N}_{2}\right] \mathrm{ZnCl}_{4}$ with atom labels and $40 \%$ probability displacement ellipsoids for non- $\mathrm{H}$ atoms 


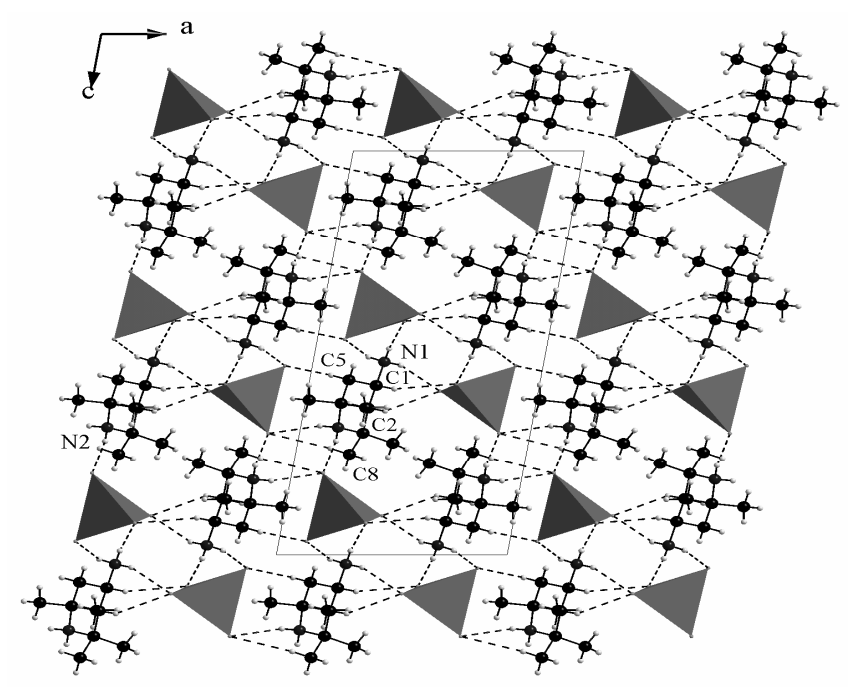

Figure 2. Projection of the structure of $\left[\mathrm{C}_{9} \mathrm{H}_{22} \mathrm{~N}_{2}\right] \mathrm{ZnCl}_{4}$ along the $\mathrm{b}$ axis. $\mathrm{ZnCl}_{4}$ is given in polyhedral representation. Hydrogen bonds are denoted by dotted lines

The $\mathrm{Zn}(\mathrm{II})$ ion is in a tetrahedral coordination environment composed of four $\mathrm{Cl}^{-}$anions. Each $\mathrm{ZnCl}_{4}{ }^{2-}$ group is connected to its four adjacent neighbour's organic cations by $\mathrm{N}-\mathrm{H}$...Cl and $\mathrm{C}-\mathrm{H} \ldots \mathrm{Cl}$ interactions involving four chlorine atoms (Table 3). The (N)-H...Cl distances, varying between 2.37 and $2.56 \AA$, are smaller than the sum od Van der Waals radii of the chlorine and hydrogen atoms $[\mathrm{r}(\mathrm{Cl})+\mathrm{r}(\mathrm{H})=2.81 \AA$ \& $]$. Consequently, these values correspond well to strong hydrogen bonds. However, the $\mathrm{C}-\mathrm{H}$... Cl hydrogen bonds play a subordinative role in stabilizing the structure ${ }^{18,19}$. Moreover, the remarkable feature in the complexe salt is the N-H...Cl hydrogen bonding which form $\mathbf{R}_{2}^{6}(\mathbf{2 6})$ of hydrogen-bonded ring type ${ }^{20}$ as shown in Figure 3.

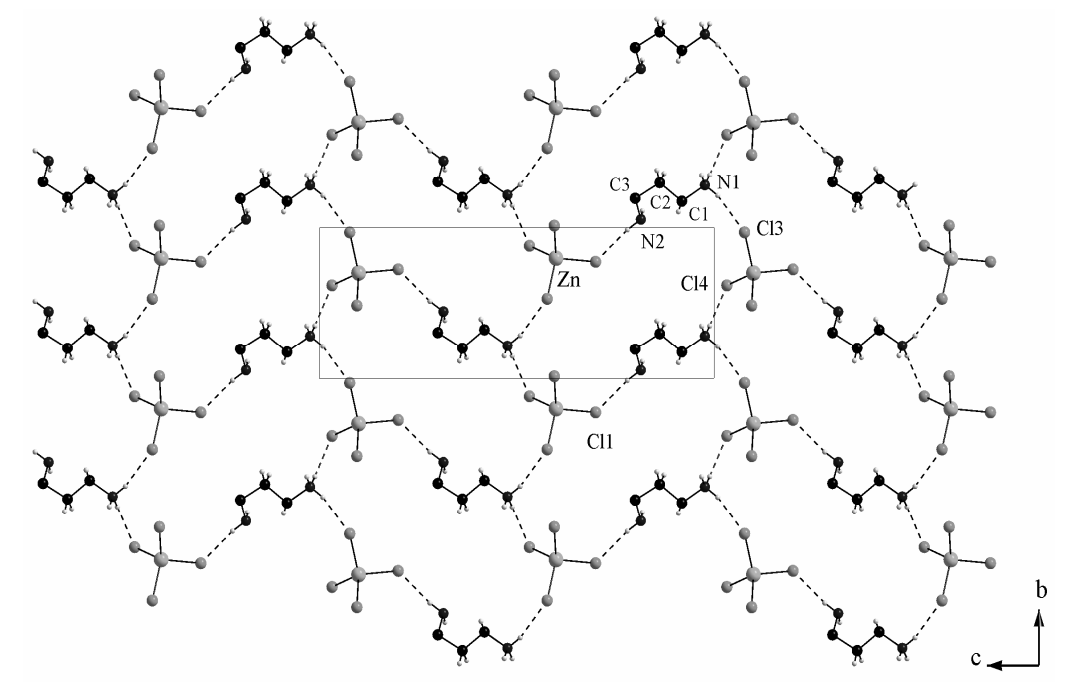

Figure 3. Hydrogen bonding which form representation of $\mathbf{R}_{2}^{6}(\mathbf{2 6})$ N-H...Cl hydrogenbonded ring type in $\left[\mathrm{C}_{9} \mathrm{H}_{22} \mathrm{~N}_{2}\right] \mathrm{ZnCl}_{4}$ 
Previous studies of tetrachlorozincates have shown that the $\mathrm{Zn}-\mathrm{Cl}$ bond lengths and $\mathrm{Cl}-\mathrm{Zn}-\mathrm{Cl}$ bond angles in the $\mathrm{ZnCl}_{4}{ }^{2-}$ anion are not equal to one another but depend on the environment around the anion ${ }^{21}$. For example, the presence of hydrogen bonds or repulsions influences appreciably these geometrical parameters. Indeed, the fact that the $\mathrm{Zn}-\mathrm{Cl} 1$ bond length is the longest meets the expectation derived from hydrogen bonding effects, because the atom $\mathrm{Cl} 1$ accepts three hydrogen bonds, while the remaining $\mathrm{Cl} 2, \mathrm{Cl} 3$ and $\mathrm{Cl} 4$ chlorine atoms are doubly acceptors (Table 3 ). However, the mean values of the $\mathrm{Zn}$ - $\mathrm{Cl}$ bond lengths and $\mathrm{Cl}-\mathrm{Zn}-\mathrm{Cl}$ bond angles are 2.266(5) $\AA$ and $109.47(2)^{\circ}$, respectively, are in agreement with those found in 2,6-Xylidinium tetrachlorozincate dihydrate [ $2.267 \AA$ and $\left.109.5^{\circ}\right]^{22}$. In the title hybrid material, the $\mathrm{Cl}-\mathrm{Zn}-\mathrm{Cl}$ angles range from $106.12(2)$ to $113.86(2)^{\circ}$. These values indicate that the geometry around the zinc atom is approximately tetrahedral, according to the Bis(quinolinium) tetrachlorozincate(II) where the corresponding limit angles are 106.33(3) and 112.34(4) ${ }^{\circ}$. However, in the 4-(2-ammonioethyl)) morpholin-4ium tetrachlorozincate these angle values vary from $98.90(4)$ to $114.74(4)^{\circ}$ indicating that the coordination geometry of $\mathrm{Zn}$ atom could be regarded as a distorted tetrahedron ${ }^{24}$.

Table 3. Hydrogen-bond geometry $\left(\AA,^{\circ}\right)$ in $\left[\mathrm{C}_{9} \mathrm{H}_{22} \mathrm{~N}_{2}\right] \mathrm{ZnCl}_{4}$

\begin{tabular}{|c|c|c|c|c|}
\hline D-H...A & D-H $(\AA)$ & H...A $(\AA)$ & $\mathrm{D}-\mathrm{A}(\AA)$ & $\mathrm{D}-\mathrm{H} \ldots \mathrm{A}\left({ }^{\circ}\right)$ \\
\hline N2-H7 ...Cl1 & 0.88 & 2.37 & $3.239(1)$ & 169 \\
\hline N2-H8...Cl1 & 0.88 & 2.56 & $3.428(2)$ & 166 \\
\hline C8-H19...Cl1 & 0.94 & 2.85 & $3.645(8)$ & 143 \\
\hline N1-H3 ...Cl2 & 0.88 & 2.48 & $3.306(8)$ & 159 \\
\hline C2-H6...Cl2 & 0.97 & 2.74 & $3.574(5)$ & 144 \\
\hline $\mathrm{N} 1-\mathrm{H} 2 \ldots \mathrm{Cl} 3$ & 0.87 & 2.40 & $3.257(2)$ & 166 \\
\hline $\mathrm{C} 1-\mathrm{H} 4 \ldots \mathrm{Cl} 3$ & 0.96 & 2.72 & $3.600(1)$ & 153 \\
\hline N1-H1 ...Cl4 & 0.88 & 2.43 & $3.256(5)$ & 155 \\
\hline C5-H10...Cl4 & 0.96 & 2.80 & $3.749(4)$ & 170 \\
\hline
\end{tabular}

\section{Infrared spectroscopy}

The IR spectrum of crystalline $\left[\mathrm{C}_{9} \mathrm{H}_{22} \mathrm{~N}_{2}\right] \mathrm{ZnCl}_{4}$ is shown in Figure 4. To assign the IR bands to vibrational modes, we have examined the modes and frequencies observed in similar compounds ${ }^{25-27}$. In the high-frequency region, broad bands between 3600 and $2600 \mathrm{~cm}^{-1}$ are attributed to the stretching vibrations: $v(\mathrm{~N}-\mathrm{H})$ and $v(\mathrm{C}-\mathrm{H})^{28}$. The vibrations between 1650 and $1200 \mathrm{~cm}^{-1}$ are assigned to bending and stretching modes $\delta(\mathrm{N}-\mathrm{H}), v(\mathrm{C}-\mathrm{C})$ and $v(\mathrm{C}-\mathrm{N}){ }^{29,30}$. The bands vibrations between 1000 and $750 \mathrm{~cm}^{-1}$ are attributed to out of plane bending modes $\gamma(\mathrm{C}-\mathrm{H}), \gamma(\mathrm{C}-\mathrm{C})$ and $\gamma(\mathrm{C}-\mathrm{N})^{31}$.

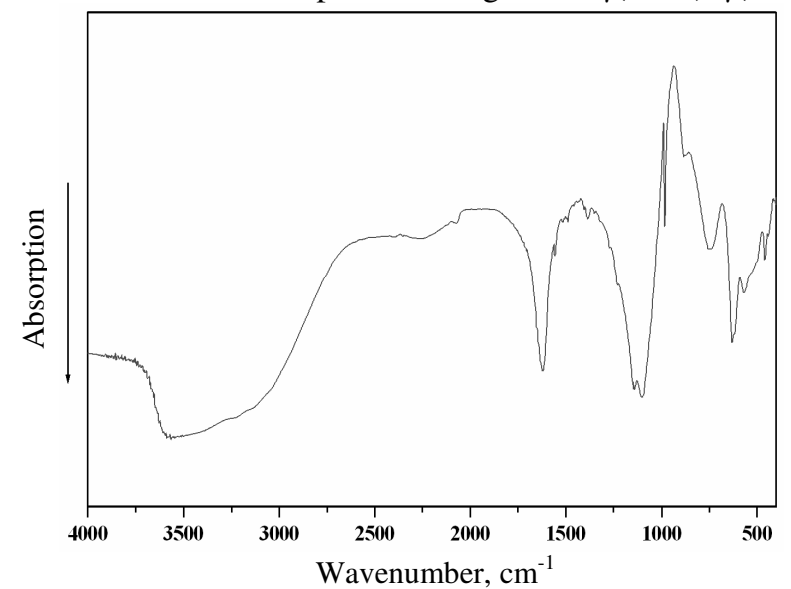

Figure 4. IR absorption spectrum of $\left[\mathrm{C}_{9} \mathrm{H}_{22} \mathrm{~N}_{2}\right] \mathrm{ZnCl}_{4}$ 


\section{Thermal behaviour}

The simultaneous TGA-DTA curves of crystalline $\left[\mathrm{C}_{9} \mathrm{H}_{22} \mathrm{~N}_{2}\right] \mathrm{ZnCl}_{4}$ are given in Figure. 5 . The DTA curve shows that this compound undertakes a series of endothermic peaks in a wide temperature range $\left(240-500{ }^{\circ} \mathrm{C}\right)$. The most important one appears at about $257.34{ }^{\circ} \mathrm{C}$. It corresponds to a melting point, which is in good agreement with the result obtained by the capillarity tube method. The important weight loss observed in this temperature region is attributed to the degradation of the organic entity confirmed by the black deposit of carbon obtained at the end of the experiment.

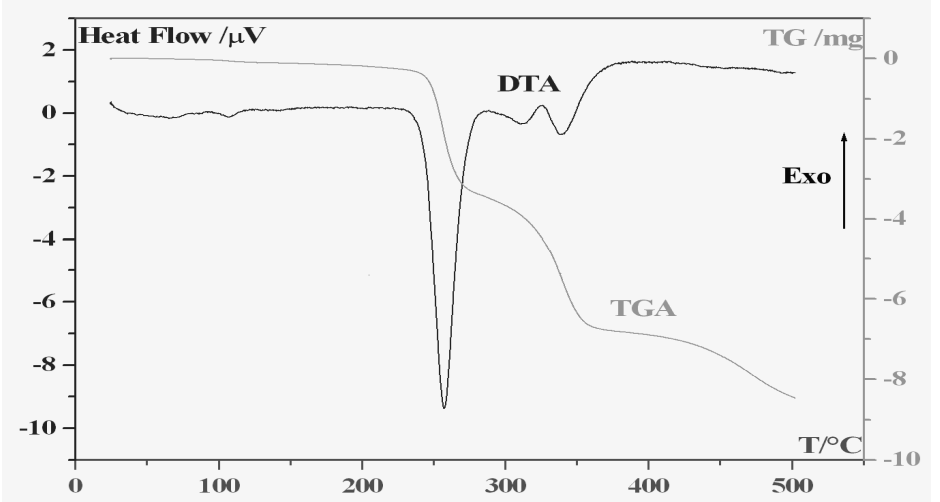

Figure 5. DTA and TGA curves of $\left[\mathrm{C}_{9} \mathrm{H}_{22} \mathrm{~N}_{2}\right] \mathrm{ZnCl}_{4}$ at rising temperature

\section{Impedance spectroscopy}

Typical impedance spectra were carried out in the temperature range 383-423 $\mathrm{K}$ for electrolyte (Figure 6). The total conductivity of the samples has been obtained from the extrapolated intercept of the semicircle with the real axis at low frequency. This intercept combines volume and grain boundary components of the total resistance. Figure 7 shows the temperature dependence of the electrical conductivity $\sigma$ of the title compound. The increase of the conductivity as a function of temperature proves that this material has a non-metal behaviour.

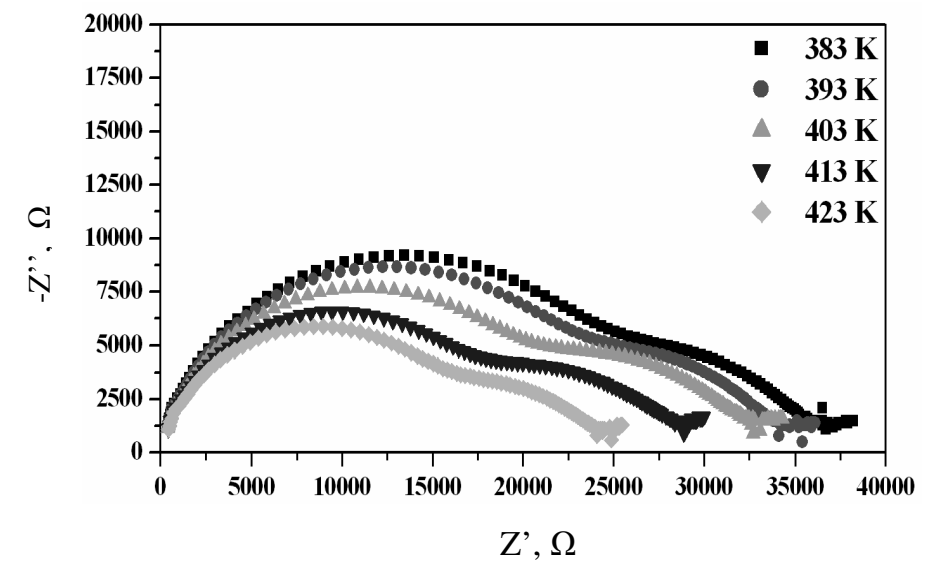

Figure 6. Typical impedance diagrams obtained under air using symmetric cells for $\left[\mathrm{C}_{9} \mathrm{H}_{22} \mathrm{~N}_{2}\right] \mathrm{ZnCl}_{4}$ 


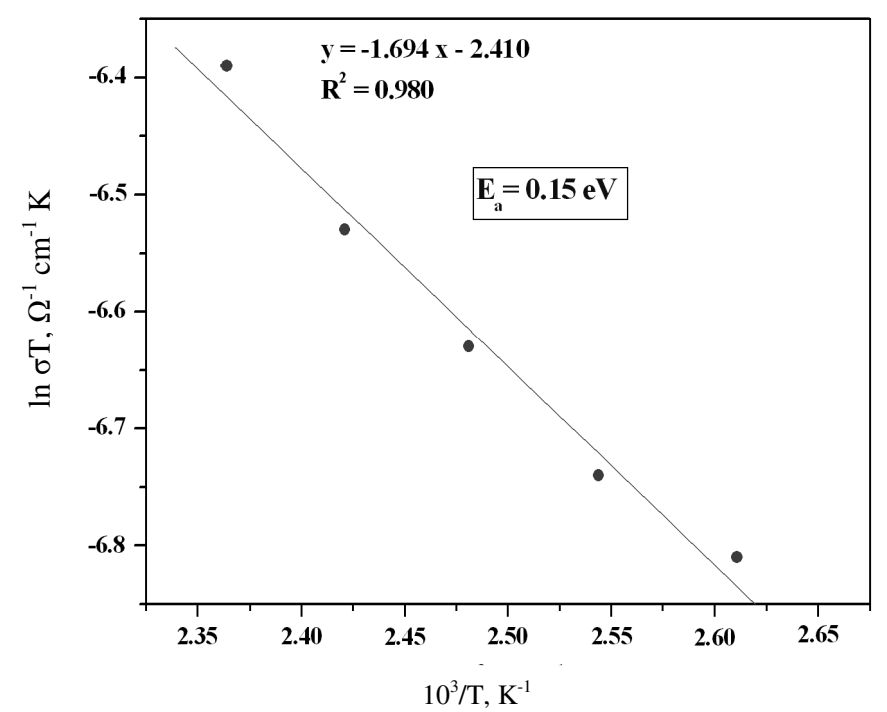

Figure 7. Temperature dependence of the conductivity of $\left[\mathrm{C}_{9} \mathrm{H}_{22} \mathrm{~N}_{2}\right] \mathrm{ZnCl}_{4}$

If the carrier concentration remains constant throughout the temperature range measured, the Arrhenius diagram should be a linear plot $\left(\log (\sigma \mathrm{T}) v s .10^{3} / \mathrm{T}\right)$, following the relation:

$$
\sigma=\frac{A_{0}}{T} \exp \left(-\frac{E_{a}}{k T}\right)
$$

Where $E_{a}$ is the activation energy, $\mathrm{k}$ and $\mathrm{T}$ are the Boltzmann constant and the absolute temperature, respectively. The $\mathrm{A}_{0}$ constant includes the carrier concentration as well as other material dependent parameters ${ }^{32,33}$. The Arrhenius plot shows that the activation energy is practically constant in the chosen temperature range which can be explained by only one mechanism of conduction. The obtained value for the activation energy $(0.15 \mathrm{eV})$ is relatively weak and is in favour of protonic conductivity mechanism.

\section{Conclusion}

The new complex $\left[\mathrm{C}_{9} \mathrm{H}_{22} \mathrm{~N}_{2}\right] \mathrm{ZnCl}_{4}$ was prepared as single crystals at room temperature and characterized by various physicochemical studies. The crystal structure contains isolated slightly distorted tetrahedral $\mathrm{ZnCl}_{4}{ }^{2-}$ anions held to the 4-ammmonio-2,2,6,6tetramethylpiperidinium cations by multiple hydrogen bonds which lead to an open framework architecture. When heated, the title compound undergoes a decomposition of the organic entity in a large temperature range. The activation energy issued form the impedance spectra suggests a protonic conductivity mechanism for this materials.

\section{Supplementary material}

Crystallographic data for the structural analysis have been deposited at the Cambridge Crystallographic Data Centre, CCDC No CCDC 736280. Copies of this information may be obtained free of charge from The Director, CCDC, 12 Union Road, Cambridge, CB2 IEZ, UK(fax: +44-1226-336033; e-mail: deposit@ccdc.cam or www:http:/www.ccdc.cam.ac.uk).

\section{Acknowledgments}

We would like to acknowledge the support provided by the Secretary of State for Scientific Research and Technology of TUNISIA. 


\section{References}

1. Wang J T, Savinell R F, Wainright J, Litt M and Yu H, Electrochim Acta., 1996, 41, 193-197.

2. Coombs N, Khuehniani D, Silver S, Ozin G A, Shen G C, Sokolov I and Yang H, $J$ Chem Soc Dalton Trans., 1997, 21, 3941.

3. Mitzi D B, J Chem Soc Dalton Trans., 2001, 1.

4. Mitzi D B, Prog Inorg Chem., 1999, 48, 1.

5. Qin J, Dai C, Liu D, Chen C, Wu B, Yang C and Zhan C, Coord Chem Rev., 1999, 188, 23.

6. Jiang M and Fang Q, Adv Mater., 1999, 11, 1147.

7. Ogawa M and Kuroda K, Chem Rev., 1995, 95, 399.

8. Pécaut J, Le Fur Y, Levy J P and Masse R, J Mater Chem., 1993, 3, 333.

9. Lacroix P G, Chem Mater., 2001, 13, 3495.

10. Lacroix P G, Clément R, Nakatani K, Delaire J A, Zyss J and Ledoux I, Sci., 1994, 263, 658 .

11. Bringley J F and Rajeswaran M, Acta Cryst., 2006, E62, m1304.

12. Brammer L, Swearingen J K, Bruton E A and Sherwood P, Proc Natl Acad Sci USA, 2002, 99, 4956-4961.

13. Altomare A, Burla M C, Camalli M, Cascarano G L, Giacovazzo C, Guagliardi A, Moliterni A G G, Polidori G and Spagna R, J Appl Cryst., 1999, 32, 115-119.

14. Betteridge P W, Carruthers J R, Cooper R I, Prout K and Watkin D J, J Appl Cryst., 1998, 36, 1487.

15. Brandenburg K, Diamond Version 2.0 Impact GbR, Bonn, Germany, 1998.

16. Bauerle J E, J Phys Chem Solids, 1969, 30, 2657.

17. Macdonald J R, Impedance Spectrometry: Emphasising Solid Materials and Systems, Wiley Interscience, New York, 1987.

18. Braga D, Draper S M, Champeil E and Grepioni F, J Organomet Chem., 1999, 57, 373.

19. Janiak C and Scharmann T G, Polyhedron, 2003, 22, 1123-1133.

20. Valkonen A, Ahonen K and Kolehamainem E, Acta Cryst., 2006, C62, m290.

21. Albrecht A S, Landee C P and Turnbull M M, J Chem Crystallogr., 2003, 33, 269-276.

22. Smirani W and Rzaigui M, E-J Chem., 2009, 6(2), 569-576.

23. Valdés-Martinez J, Munoz O and Toscano R A, Acta Cryst., 2005, E61, m1590-m1592.

24. El Glaoui M, Jeanneau E, Zeller M, Lefebvre F and Ben Nasr C, Acta Cryst., 2010, E66, m791.

25. Calve N L, Romain F, Limage M H and Novak A, J Mol Struct., 1989, 200, 131.

26. Ratajczak H J, J Mol Struct., 1969, 3, 27.

27. Navak A, J Mol Struct., 1990, 217, 35-49.

28. Smirani W, Ben Nasr C and Rzaigui M, Mater Res Bull., 2004, 39, 1103.

29. Kaabi K, Rayes A, Ben Nasr C, Rzaigui M and Lefebvre F, Mat Res Bull., 2003, 38, 741.

30. Oueslati A, Ben Nasr C, Durif A and Lefebvre F, Mat Res Bull., 2005, 40, 970.

31. Oueslati A, Rayes A, Ben Nasr C and Lefebvre F, Mat Res Bull., 2005, 40, 1680.

32. Lee H Y, Oh S M, Seo I Y, Rocholl J and Wiemhöfer H D, in: Stimming U, Singhal S C, Tagawa H and Lehnert W (Eds)., Solid Oxide Fuel Cells V, Electrochemical Society, Pennington, N J Proc $5^{\text {th }}$ Intl Symp Solid Oxide Fuel Cells, 1997, 520.

33. Kim S, Yang Y L, Christoffersen R and Jacobson A J, Solid State Ionics, 1997, 104, 57.

34. Larson A C, Inclusion of Secondary Extinction in Least-squares Refinement of Crystal Structures. Crystallogr. Comput., Proc. Int. Summer Sch., 1970; Meeting Date 1969, 291. 


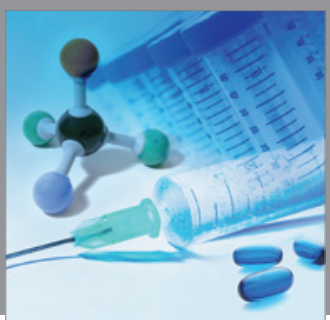

International Journal of

Medicinal Chemistry

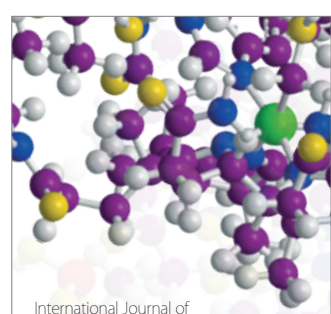

Carbohydrate Chemistry

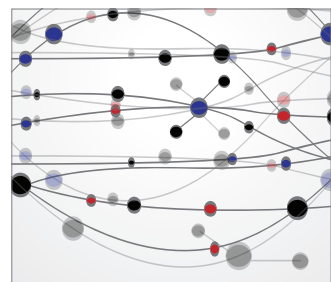

The Scientific World Journal
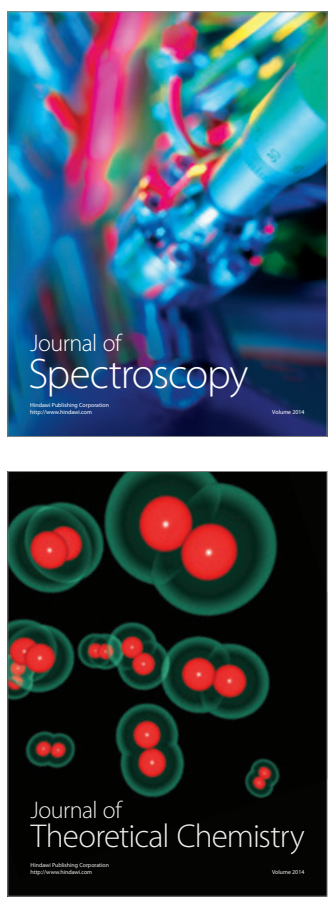
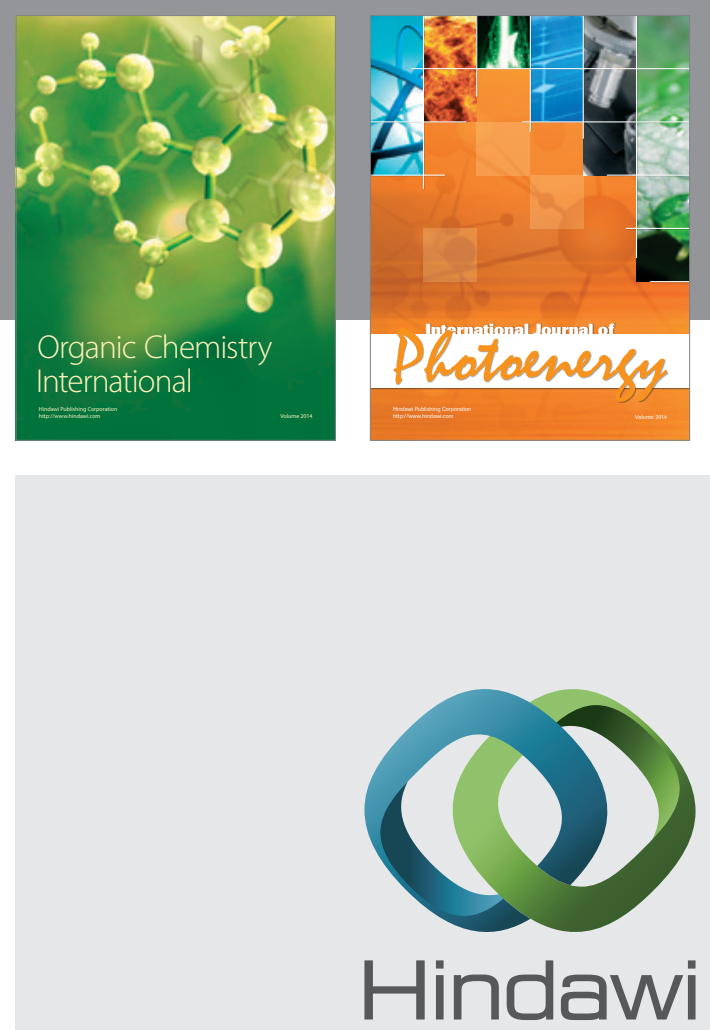

Submit your manuscripts at

http://www.hindawi.com
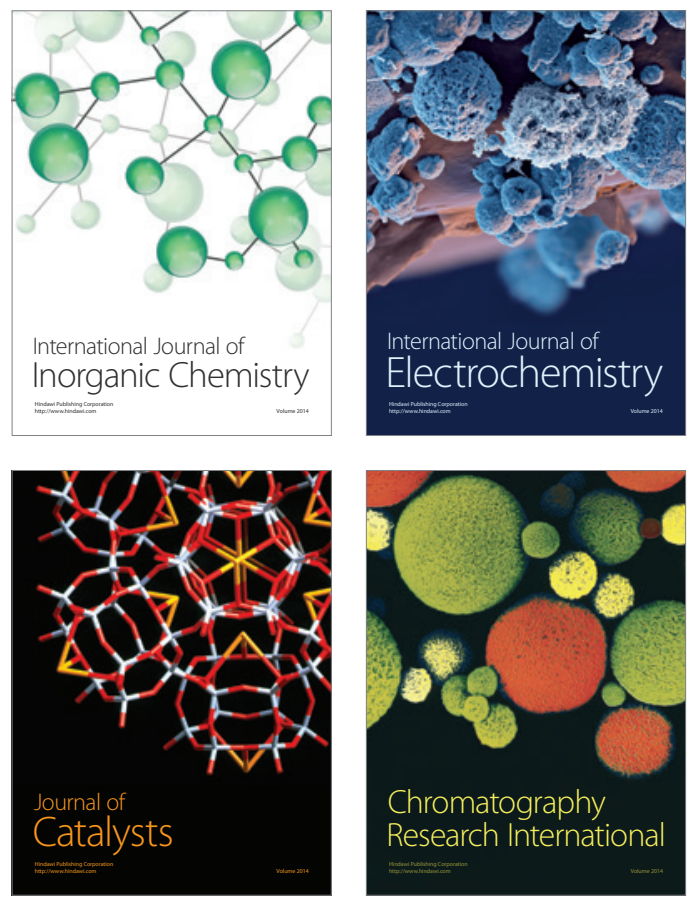
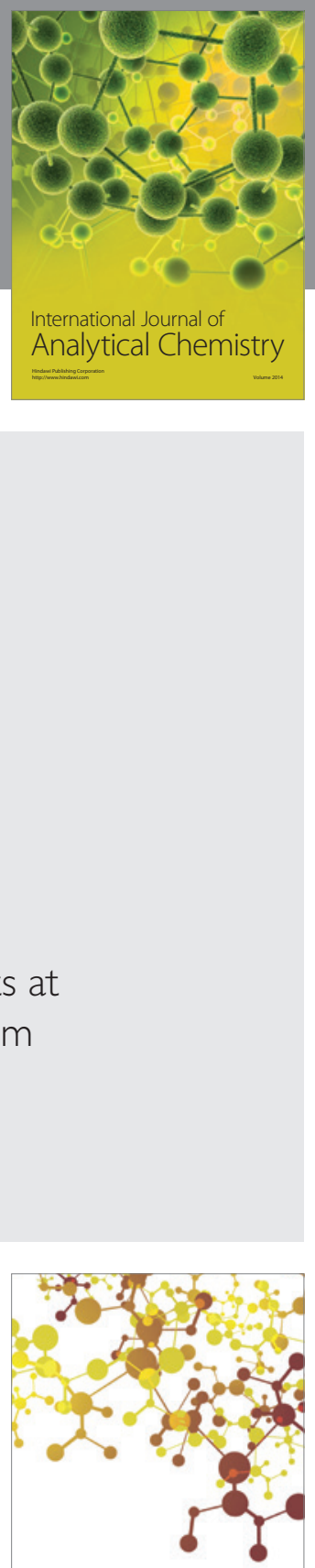

Journal of

Applied Chemistry
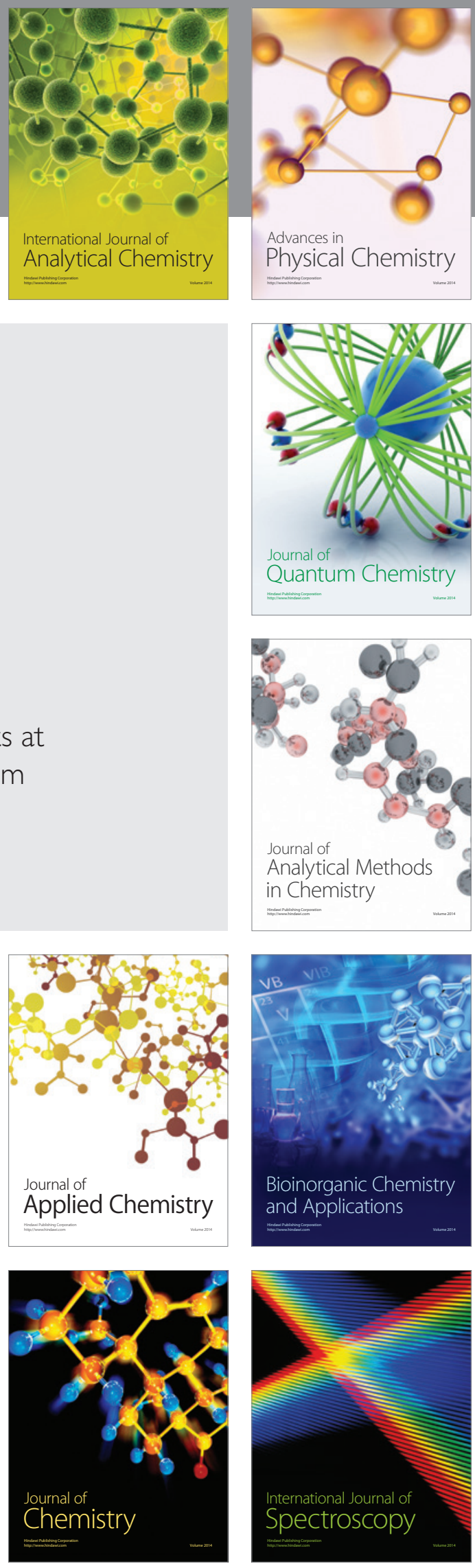